\title{
The effect of randomly distributed natural fibers on some geotechnical characteristics of a lateritic soil
}

\author{
A. K. Lawer ${ }^{1}$ (D) S. I. K. Ampadu² F. Owusu-Nimo²
}

Received: 14 December 2020 / Accepted: 4 May 2021

Published online: 17 May 2021

(c) The Author(s) 2021

OPEN

\begin{abstract}
Weak lateritic subgrades are more often than not encountered during road construction in Ghana. This makes it necessary to find economically efficient ways to improve the engineering properties of these marginal lateritic soils. The objective of this study is to investigate the effects of coconut fiber ( $30 \mathrm{~mm}, 60 \mathrm{~mm}$ and $90 \mathrm{~mm}$ fiber lengths) and palm fiber on some geotechnical characteristics of a weak lateritic subgrade. The lateritic soil was collected from the KNUST campus and blended with various percentages of the fibers varying between 0.1 and $1.0 \%$ by weight of dry soil. The mixed materials were then subjected to various laboratory tests including compaction, unconfined compression test and 4-day-soaked California bearing ratio test. From the results, it was observed that increasing the fiber content decreased the maximum dry density and increased the optimum moisture content. The inclusion of the fiber increased the soaked CBR from 7 to a maximum of 18,22 , and 25 at $30 \mathrm{~mm}, 60 \mathrm{~mm}$ and $90 \mathrm{~mm}$ fiber lengths, respectively. The unconfined compressive strength also increased from 140 to a maximum of $353 \mathrm{kPa}, 398 \mathrm{kPa}$ and $447 \mathrm{kPa}$, respectively, for $30 \mathrm{~mm}$, $60 \mathrm{~mm}$ and $90 \mathrm{~mm}$ fiber lengths. Similarly, palm fiber inclusion recorded maximum soaked CBR value of $14 \%$ and UCS value of $352 \mathrm{kPa}$. These peak values were obtained at optimum fiber contents of $0.2 \%$.
\end{abstract}

Keywords Lateritic · Coconut fiber · Palm fiber - Unconfined compression strength · California Bearing Ratio

\section{Introduction}

Low volume roads play a major role in the socioeconomic development of rural communities. However, they carry low volumes of traffic and are normally designed and built to lower standards than other categories of roads. In Ghana, less than ten percent of engineered rural roads are surface dressed. The bulk majority are unsurfaced and simply referred to as 'gravel roads.' These gravel roads consist of subgrade with up to about $150 \mathrm{~mm}$ subbase layer thickness. Lateritic soils are the most abundant naturally occurring materials used for the construction of both the subgrade and subbase layers. However, most of these lateritic soils usually have high fines content [15], thus making them unsuitable for road construction. When such materials are encountered along a road alignment during construction and are not well treated, they develop into'soft spot' section leading to premature failure of the road before their designed life. In this study, soft spots are areas of the gravel road surface (or the subgrade) which are made weak as a result of low material strength which poses problems of shear failure and excessive rutting. However, the conventional approach employed by the Feeder Roads Department in Ghana is to cut the weak section and replace it with competent compacted soil. The other way is to use

$\triangle$ A. K. Lawer, augustinelawer@yahoo.com; S. I. K. Ampadu, sikampadu@yahoo.co.uk; skampadu.coe@knust.edu.gh; F. Owusu-Nimo, frednimo@gmail.com | ${ }^{1}$ Department of Civil Engineering, Koforidua Technical University, Koforidua, E/R, Ghana. ${ }^{2}$ Department of Civil Engineering, Kwame Nkrumah University of Science and Technology, Kumasi, Ghana.

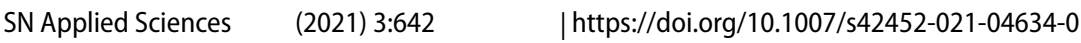


the concept of any appropriate soil improvement technology in improving these critical sections.

Since 1969, Vidal [37] proposed the use of metal strips as reinforcements in reinforced earth system which increased the shearing resistance of the soil matrix. Since then, the use of geomaterials to modify the behavior of soil has increased in executing geotechnical structures such as embankments, pavements, retaining walls, etc. Many researchers over the past years have used synthetic fibers as well as natural fibers in reinforcing soil. Muthu et al. [28] researched on the application of coconut coir fiber for improving subgrade strength characteristics of clayey sand. The result of the study showed designed pavement thickness reduction of $55 \%$ for soil reinforced with $1.2 \%$ fiber content compared to unreinforced soil. Mali and Singh [23], studied the strength behavior of reinforcing soft silty or clayey soils with randomly distributed natural and synthetic fibers. The study concluded that the fibers mobilized tensile resistance when loaded which imparted higher strength to the soil. Singh and Mittal [33] conducted a study on the use of coconut fiber to improve local subgrade soil for road construction and concluded that the composite effect of the natural fiber changes the soil from brittle to ductile behavior. Again, Chaple and Dhatrak [7] studied the performance of clayey soil when reinforced with coir fiber and concluded that the provision of coir reinforced layer reduces settlement and improves the bearing capacity ratio in a range of 1.5 to 2.66 . Babu and Vasudevan [5] reported on the response behavior of coir fiber-reinforced soil in terms of strength and stiffness. The study concluded that the stiffness of the soil was increased with fiber inclusion and the pullout resistance of synthetic fibers is less compared to that of natural fibers. Among other researches are Charan et al. [8], Kumar et al. [18], Zornberg [38], Cyrus and Babu [9], Kumar et al. [19], Marandi et al. [24], Ramesh et al. [31] and Pradhan et al. [30], Abhijith [1] and Stuti et al. [35].

In Ghana, coconut plantations occur along the coast mostly in the Greater Accra, Central and Western regions. Oil palm plantations are also predominantly found in the forest zones in the Eastern, Ashanti and Brong-Ahafo regions. Palm fibers are obtained as a by-product of palm oil production, while the coconut fibers are obtained from the coconut husk after processing for coconut oil or for human consumption of the edible part. Ghavami et al. [14] and Mattone [25] have reported on the major significance of using natural fibers in reinforcing soils as being easily available, good workability and their environmental friendliness. This laboratory study seeks to investigate the feasibility of reinforcing a lateritic subgrade material with randomly distributed natural fiber derived from coconut and palm for rural road construction.

\section{Materials and methods}

\subsection{Lateritic soil}

Bulk sample of the lateritic soil was obtained from KNUST campus at geographical coordinates $6.67209 \mathrm{~N}$ and $1.56575 \mathrm{~W}$. A trial pit of approximate size $1.5 \mathrm{~m}$ by $1.2 \mathrm{~m}$ was sunk manually and lateritic soil between the depths of $0.5 \mathrm{~m}$ to $2.0 \mathrm{~m}$ collected. The bulk sample was air-dried for three days and index property tests conducted in accordance with the methodologies outlined in BS 1377: Part 2: 1990 [6]. The cone penetrometer was used in the determination of the liquid limit test, while the particle size distribution analysis on the solid particles was conducted using wet sieving. The hydrometer test was performed on the fines portion of the soil sample using sodium hexametaphosphate as deflocculating agent. The specific gravity of the solid soil particles was determined on the air-dried samples using the gas jar method following the procedures as stipulated in BS 1377:Part 2:1990.

The lateritic soil was then subjected to the modified AASHTO compaction, unconfined compression test (UCS) and 4-day-soaked California bearing ratio (CBR) tests in accordance with ASTM D 1557-91 [2]. Soil sample was taken to the Ghana Geological Survey for chemical analysis determination using the $\mathrm{X}$-ray fluorescence spectrometer.

The summary of results on the index properties of the lateritic soil is detailed in Table 1. The study sample used in this research had liquid limit of $51 \%$, a plasticity index of $27 \%$ with a fines content of $55.04 \%$ (i.e., the percentage passing sieve size $75 \mu \mathrm{m}$ ). The particle size distribution characteristic of the soil is shown in Fig. 1 and superimposed on the grading envelope specified by the Ministry of Transport [27] for base and subbase pavement layers.

From the laboratory results, the lateritic soil classifies as A-7-6 according to the AASHTO classification system which puts it as fair to poor material for subgrade of roads. Samples with such properties are typical of lateritic soils encountered on many road projects in Ghana, hence the need to improve them through reinforcement method.

Table 2 details the summary of the chemical composition of the study soil. It is found that the lateritic soil has oxides being silica, alumina and iron oxides as the dominant oxides contributing to $68.32 \%$. The aluminum and iron oxides (i.e., the sesquioxide) constitute $32 \%$ of the chemical composition. The silica-sesquioxide ratio was evaluated to be 1.14. This shows that the study soil is true laterite because silica-sesquioxide ratio less than 1.33 is an indicative of true laterites (Lyon Associates Inc, 1971 [22]). 
Table 1 Summary of index properties test

\begin{tabular}{ll}
\hline Geotechnical characteristics & Laboratory value \\
\hline Natural moisture content (\%) & 20.8 \\
Specific gravity & 2.639 \\
Grading & \\
Gravel (\%) & 12 \\
Sand (\%) & 42 \\
Silt (\%) & 23 \\
Clay (\%) & 23 \\
Atterberg limits & \\
Liquid limit (\%) & 51 \\
Plastic limit (\%) & 24 \\
Plasticity index (\%) & 27 \\
Linear shrinkage (\%) & 13 \\
Compaction & \\
Maximum dry density (Mg/m ${ }^{3}$ ) & 1.928 \\
Optimum moisture cont. (\%) & 13.9 \\
CBR-4-day soaked (\%) & 7 \\
CBR swell (\%) & 0.62 \\
Classification & \\
AASHTO & $\mathrm{A}-7-6$ \\
USCS & $\mathrm{CH}$ \\
\hline
\end{tabular}

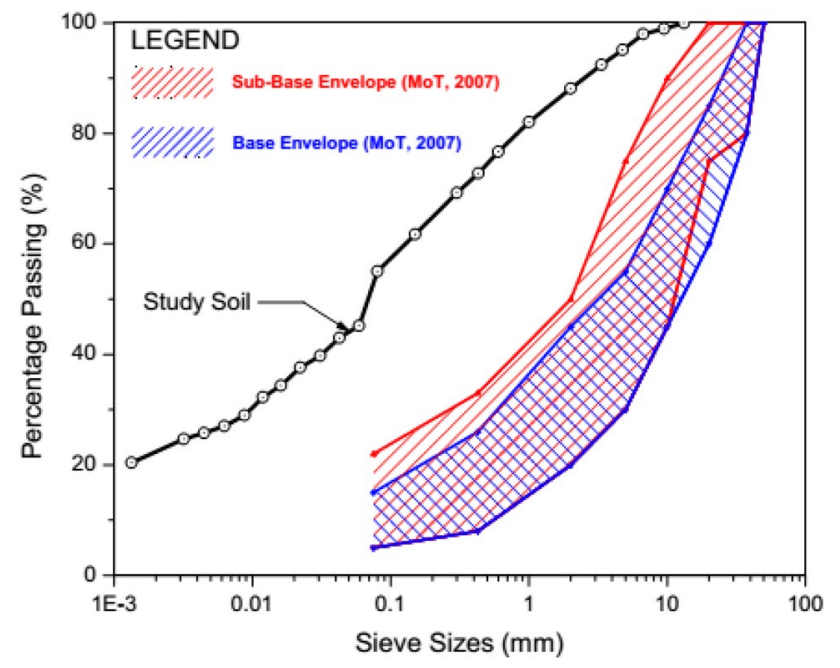

Fig. 1 Grading characteristics of study soil

\subsection{Natural fibers}

The processed coconut fiber (Fig. 2) was obtained from a commercial firm. The coconut fibers were de-stranded and cut into lengths of $30 \mathrm{~mm}, 60 \mathrm{~mm}$ and $90 \mathrm{~mm}$. The palm fiber as shown in Fig. 3 was obtained from an oil mill. For the palm fibers, no cutting was done because the fiber was of uniform length ranging between 30 to $35 \mathrm{~mm}$. However, the palm fibers were washed with tap
Table 2 Chemical composition of the soil

\begin{tabular}{lc}
\hline Major oxides & $\begin{array}{c}\text { Concentra- } \\
\text { tion (wt\%) }\end{array}$ \\
\hline $\mathrm{SiO}_{2}$ & 36.32 \\
$\mathrm{Al}_{2} \mathrm{O}_{3}$ & 25.56 \\
$\mathrm{Fe}_{2} \mathrm{O}_{3}$ & 6.44 \\
$\mathrm{Na}_{2} \mathrm{O}$ & 0.91 \\
$\mathrm{MgO}$ & 0.96 \\
$\mathrm{~K}_{2} \mathrm{O}$ & 0.98 \\
$\mathrm{CaO}$ & 0.1 \\
$\mathrm{P}_{2} \mathrm{O}_{5}$ & 0.11 \\
$\mathrm{MnO}$ & 0.03 \\
$\mathrm{TiO}_{2}$ & 0.83 \\
$\mathrm{SO}_{3}$ & 0.09 \\
$\mathrm{Total}$ & 72.33 \\
\hline
\end{tabular}

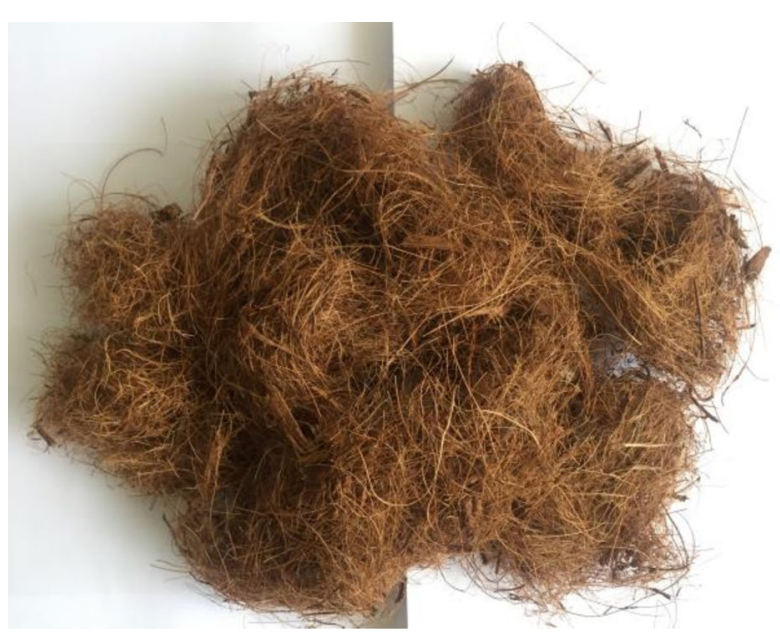

Fig. 2 Coconut fiber

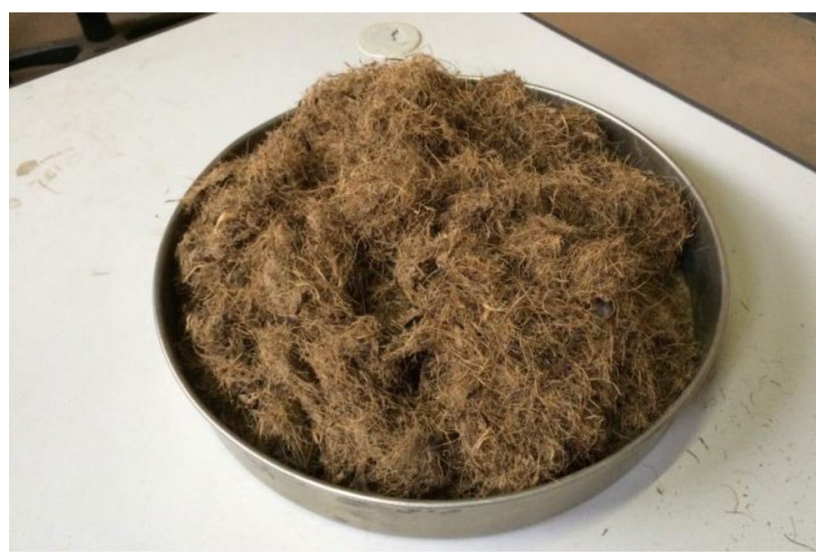

Fig. 3 Palm fiber 
water and rinsed thoroughly to remove the palm oil. Diameter of the fibers was determined using a pair of calipers upon averaging three sets of readings. The specific gravity of the fibers was determined using kerosene by the pycnometer method. Water absorption test was conducted on the two fibers at their natural moisture contents.

The surface characteristics of the 'as-received' fibers and fibers embedded in soil for 14 days, 30 days and 60 days were observed using the Scanning Electron Microscopy (SEM) SU8000 Hitachi microscope at different magnifications and $2 \mathrm{kV}$ accelerating voltage. The chemical composition of the fibers, namely cellulose, hemicellulose and lignin content, was determined on both the coconut fiber and the palm fiber.

\subsection{Soil-fiber specimen}

Table 3 is a summary of test program followed in this investigation. The lateritic soil sample and the fiber were thoroughly mixed by hand to obtain uniform soil-fiber mixes. The fibers were added in percentages of $0.1 \%$, $0.2 \%, 0.3 \%, 0.4 \%, 0.6 \%, 0.8 \%$ and $1.0 \%$ by weight of the dry soil.

\subsubsection{Compaction test}

For the compaction test, $7000 \mathrm{~g}$ of the riffled air-dried lateritic soil was weighed. Then $0.1 \%$ of $30 \mathrm{~mm}$ coconut fiber was calculated by weight of the dry soil and weighed. The soil and fiber were thoroughly mixed by hand adding water of $3 \%$ to attain uniform mix. The mixture was compacted using the BS 1377: Part 4:1990 (equivalent ASTM D 1557-91) specification. The compacted sample was reused by compacting the same sample each time but increasing the water content by about 3\%.

This is repeated for the different fiber contents of $0.1 \%, 0.2 \%, 0.3 \%, 0.4 \%, 0.6 \%, 0.8 \%$ and $1.0 \%$ for palm fiber and coconut fiber of $60 \mathrm{~mm}$ and $90 \mathrm{~mm}$ lengths. The optimum moisture content (OMC) and maximum dry density (MDD) were evaluated for each fiber type, fiber

Table 3 Summary of testing program

\begin{tabular}{llllll}
\hline Test type & Control & \multicolumn{2}{c}{ Coconut fiber length } & Palm fiber \\
\cline { 3 - 5 } & & $30 \mathrm{~mm}$ & $60 \mathrm{~mm}$ & $90 \mathrm{~mm}$ & \\
\hline Compaction & $\sqrt{ }$ & $\sqrt{ }$ & $\sqrt{ }$ & $\sqrt{ }$ & $\sqrt{ }$ \\
UCS & $\sqrt{ }$ & $\sqrt{ }$ & $\sqrt{ }$ & $\sqrt{ }$ & $\sqrt{ }$ \\
CBR & $\sqrt{ }$ & $\sqrt{ }$ & $\sqrt{ }$ & $\sqrt{ }$ & $\sqrt{ }$ \\
\hline
\end{tabular}

length and fiber content. The results have been summarized and discussed.

\subsubsection{Unconfined compression strength test}

In the unconfined compression strength (UCS) test, specimens were prepared at optimum moisture content (OMC) and maximum dry densities (MDD) obtained from the compaction test. The UCS samples were prepared at OMC and MDD as studies have shown that maximum soil strength is attained at this region of the compaction curve. Faure and Da Mata [12] conducted a study on the strength of soils along the complete compaction curve and the results showed that the maximum UCS values were attained when samples were prepared and tested at the OMC and MDD. With regard to triaxial tests, the samples recorded the maximum cohesion at the OMC. Also, study by Hua Li [17] on fine grained soils and their engineering behaviors showed similar trend with soils attaining maximum strength when compacted at OMC and MDD.

First, $3000 \mathrm{~g}$ of the riffled air-dried lateritic soil was weighed. Then, $0.1 \%$ of $30 \mathrm{~mm}$ coconut fiber length was calculated by weight of the dry soil. Then, the amount of water equivalent to the OMC making allowance for the existing water content of the soil was added to the soil-fiber and thoroughly mixed until a uniform mix was attained. The uniform mix was compacted in a split mold of $100 \mathrm{~mm}$ in diameter and $200 \mathrm{~mm}$ in height. The inside wall of each mold was lubricated with oil before compaction to facilitate the extrusion of the compacted specimens from the mold. The compacted sample was extruded using the sample extruder. The UCS test on the prepared specimen was conducted in accordance with ASTM D 2166-98a [4] at a constant strain rate of $0.33 \mathrm{~mm} / \mathrm{min}$. The results have been summarized and discussed.

The test procedure was repeated for soil-fiber mixes having fiber contents of $0.1 \%, 0.2 \%, 0.3 \%, 0.4 \%, 0.6 \%, 0.8 \%$ and $1.0 \%$ for coconut fiber lengths of $60 \mathrm{~mm}$ and $90 \mathrm{~mm}$ and palm fiber.

\subsubsection{California bearing ratio test}

For the California bearing ratio (CBR) test, $7000 \mathrm{~g}$ of airdried lateritic soil passing through $20 \mathrm{~mm}$ sieve size was first weighed. This was followed by weighing $0.1 \%$ of the $30 \mathrm{~mm}$ coconut fiber by weight of the dry lateritic soil. The weighed soil and fiber were added and mixed with water to achieve the OMC until a uniform mix was attained. The uniform soil-fiber mix was divided into approximately five equal portions. Each portion was compacted in accordance with BS 1377: Part 4:1990 using the CBR mold. The prepared specimen was soaked for four days before testing in accordance with ASTM D 1883-99 [3]. 
The test procedure was repeated for the different fiber contents of $0.1 \%, 0.2 \%, 0.3 \%, 0.4 \%, 0.6 \%, 0.8 \%$ and $1.0 \%$ for palm fiber and coconut fiber lengths of $60 \mathrm{~mm}$ and $90 \mathrm{~mm}$ lengths. The soaked CBR values of the different fiber types, fiber lengths and fiber content have been summarized and discussed.

Table 4 Physical properties and chemical composition of fiber

\begin{tabular}{lll}
\hline Fiber characteristics & Coconut fiber & Palm fiber \\
\hline Physical properties & & \\
Color & Light brown & Brown \\
Water absorption (\%) & 181 & 138 \\
Fiber diameter (mm) & 0.5 & 0.5 \\
Specific gravity & 1.342 & 1.102 \\
Chemical composition & & \\
Cellulose (\%) & 30.3 & 28.8 \\
Hemi-cellulose (\%) & 17.1 & 22.3 \\
Lignin (\%) & 41.3 & 30.1 \\
\hline
\end{tabular}

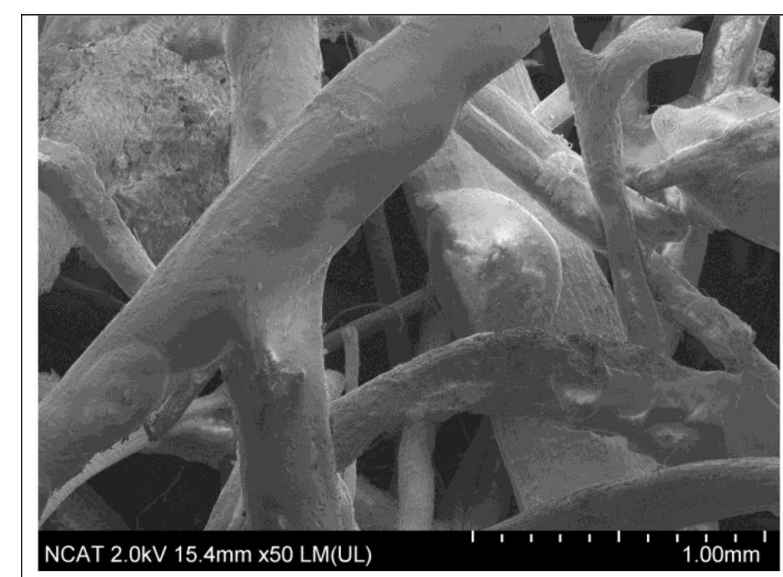

(a)

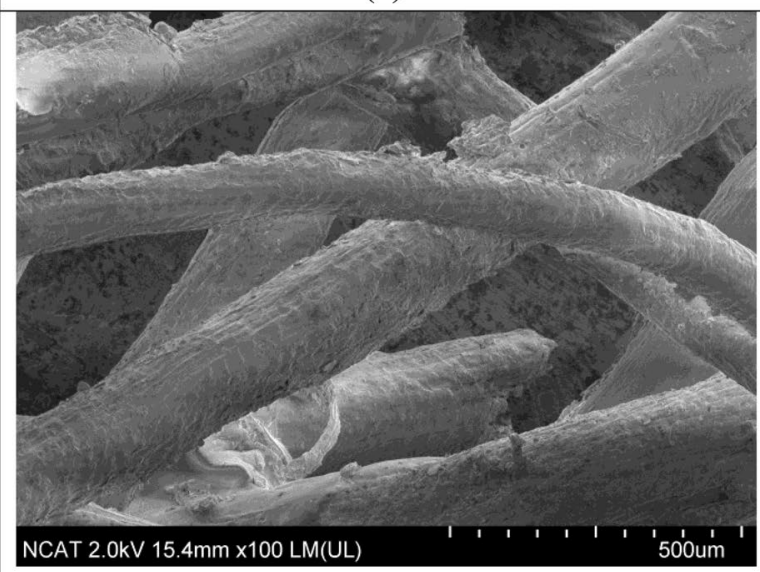

(c)

\section{Results and discussions}

\subsection{Physical and chemical properties of fibers}

The physical properties and the chemical composition of the fiber types are detailed in Table 4. The results showed the two fiber types had high lignin content, which is a complex hydrocarbon polymer. This makes the fibers exhibit good properties when used as soil reinforcement. Enokela and Alada [11] have reported that natural fibers having high lignin content and low cellulose content are strong, resilient and highly durable. Again, it has also been reported that the rate of fiber deterioration is very slow when the lignin content is high [34].

The surface morphology of the fibers obtained from the analysis of the SEM images at different fiber conditioning (thus 'as received,' 14 -day soaked, 30-day soaked and 60-day soaked) is shown in Figs. 4 and 5 for coconut and palm fiber, respectively.

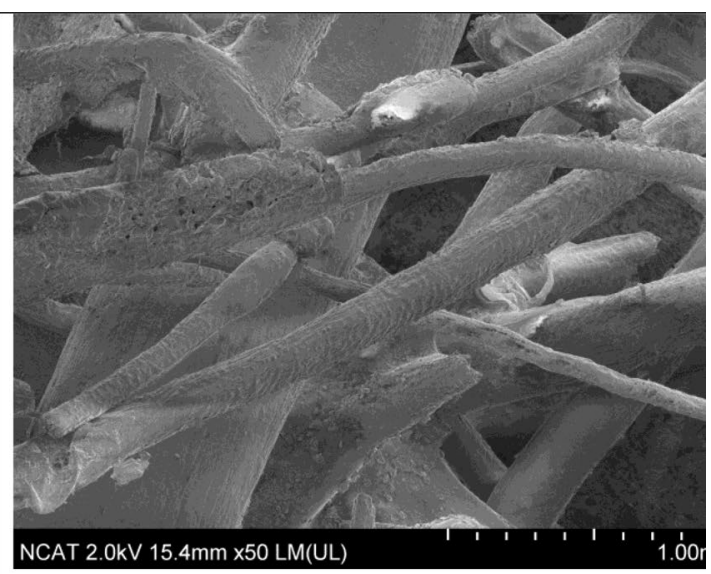

(b)

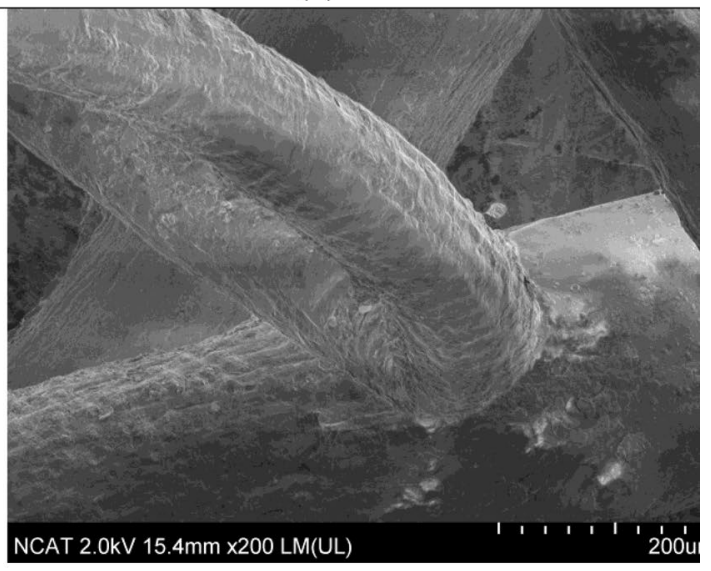

(d)

Fig. 4 SEM image of coconut fiber at different conditions. a As received b 14-day soaked $\mathbf{c}$ 30-day soaked $\mathbf{d}$ 60-day soaked 


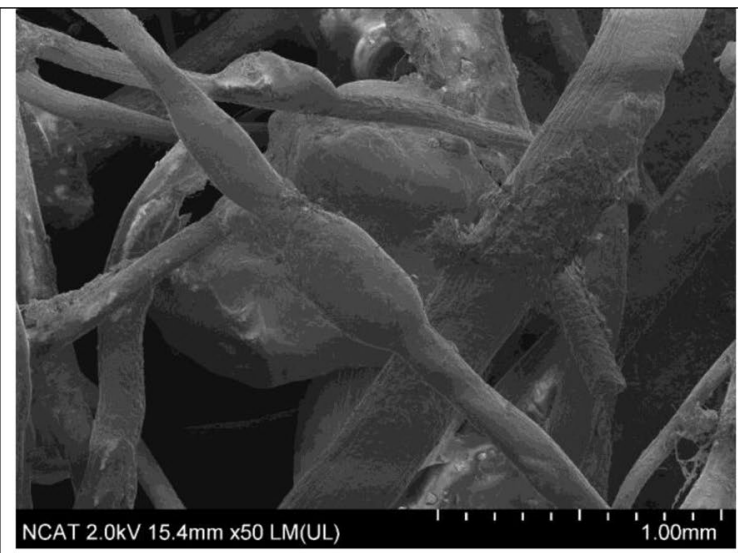

(a)

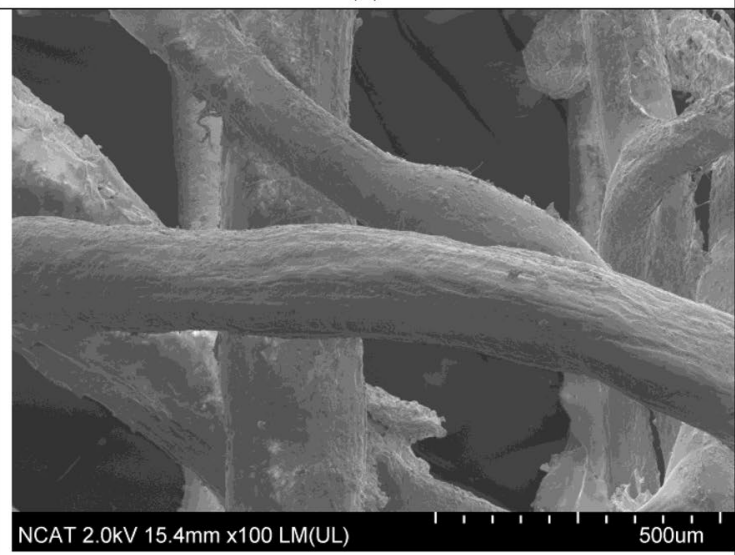

(c)

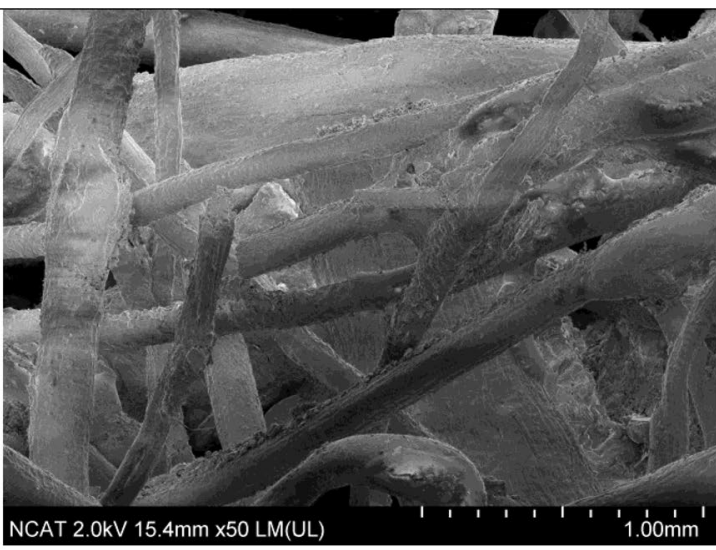

(b)

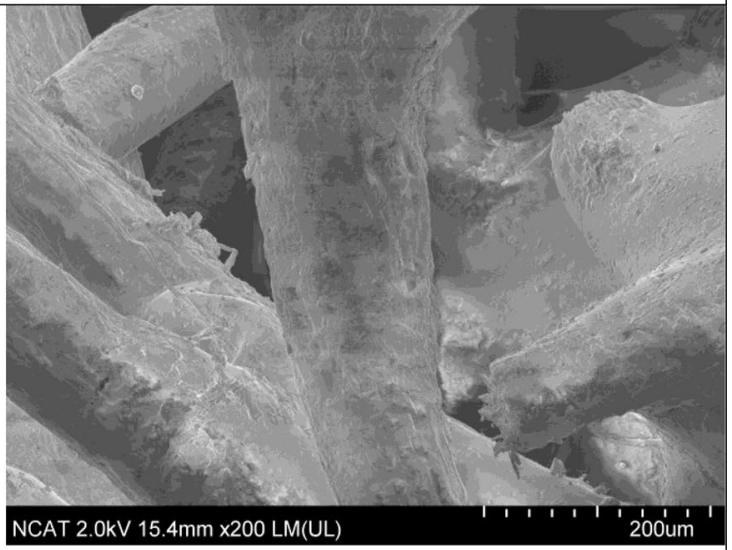

(d)

Fig. 5 SEM image of palm fiber at different conditions. a As received b 14-day soaked c 30-day soaked $\mathbf{d}$ 60-day soaked

Comparing the SEM images of both coconut and palm fibers, those embedded in soil show that the structure of the fibers appear to reflect a flocculated structure [26]. However, the intensity of the flocculation appears to be slightly intense with increase in number of days for fiber embedment. The general effect of the flocculated structure of the fiber is an improved fiber interface and hence increases the interfacial shear resistance.

\subsection{Effect of fiber content, fiber length and fiber type on compaction}

Figure 6 is a typical compaction characteristic curve of $90 \mathrm{~mm}$ coconut fiber-reinforced soil which shows the effect of fiber inclusion at varying fiber content on the compaction parameters.

The variations of optimum moisture content (OMC) and maximum dry density (MDD) with varying fiber contents and fiber lengths are shown in Figs. 7 and 8, respectively. It is found that the addition of fiber irrespective of the fiber type and fiber length leads to an increase in the OMC.

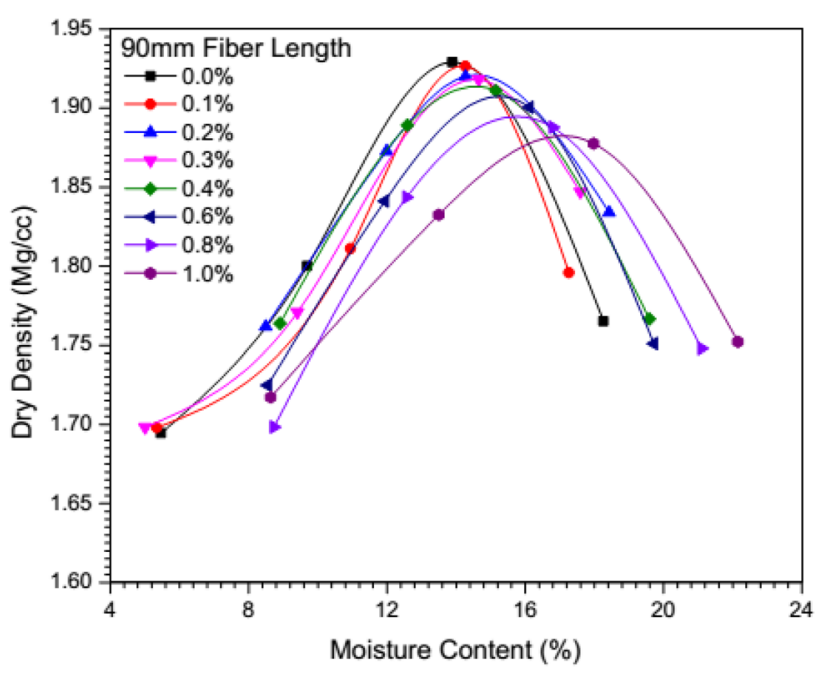

Fig. 6 Compaction characteristics of $90 \mathrm{~mm}$ coconut fiber-reinforced soil 


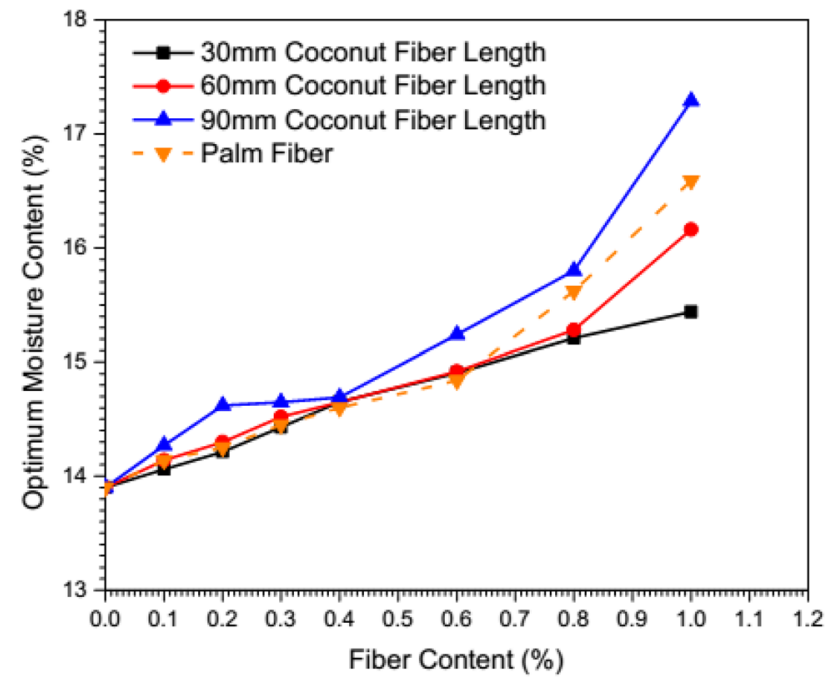

Fig. 7 Variation of OMC with fiber contents and fiber lengths

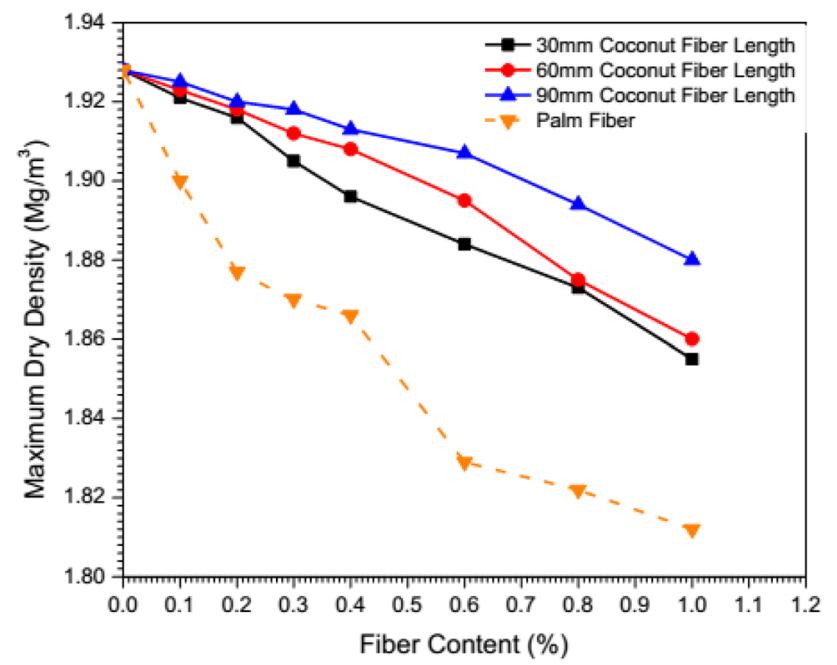

Fig. 8 Variation of MDD with fiber contents and fiber lengths

However, the OMC increased with increasing fiber content. Up until fiber content of $0.8 \%$, the rate of increase in OMC with fiber content was almost the same for palm fiber, at $30 \mathrm{~mm}$ and $60 \mathrm{~mm}$ coconut fiber lengths. The OMC was slightly higher for the $90 \mathrm{~mm}$ coconut fiber length. Beyond the $0.8 \%$ fiber content, the rate of increase in OMC was drastic particularly at $90 \mathrm{~mm}$ fiber length. The increases in $\mathrm{OMC}$ are due to the high water absorption properties of the fibers which were determined to be $181 \%$ for coconut fiber and $138 \%$ for palm fiber.

On the other hand, as the fiber content increases the maximum dry density decreases for the different fiber lengths and fiber types. From Fig. 8, the decrease in MDD generally shows a linear trend for all the coconut fiber lengths. These reductions in MDDs were due to the addition of fibers of light weight (specific gravity of 1.342 and 1.102 for coconut fiber and palm fiber, respectively) compared to the lateritic soil (having specific gravity of 2.639). From the plots, the rate of change in both the OMCs and MDDs was not uniform with increase in fiber content for all cases of fiber length and fiber type.

Similar results of MDD and OMC were reported by Marandi et al. [24] on the use of palm fibers randomly distributed in reinforcing silty sand soils, Santhi and Sayida [32] on the behavior of black cotton soil when reinforced with sisal fiber and Lekha et al. [20] on lateritic soil stabilized with arecanut coir.

From Fig. 6, the general shape of the compaction curves for fiber contents of $0.1 \%$ to $0.4 \%$ is that the MDD and OMC are approached more gradually from the dry side of the $\mathrm{OMC}$ than the wet side. However, at higher fiber content of $0.6 \%$ to $1.0 \%$, the shapes of the compaction curves show that the OMC and MDD are approached faster from the dry side of the OMC. From the compaction curves, it is clear that at higher fiber contents the reinforcing fibers impede the compaction process resulting in a lighter material. Also, at higher fiber content, the soil fiber composites form a flocculated structure which results in the reinforced soil having higher moisture content, void ratio and reduces compressibility resulting in the shapes of these compaction curves for $0.6 \%$ to $1.0 \%$ fiber contents.

\subsection{Effect of fiber on strength characteristics}

\subsubsection{California bearing ratio (CBR)}

Typical load-penetration relationships for 4-day-soaked CBR with varying fiber content of $90 \mathrm{~mm}$ coconut fiber

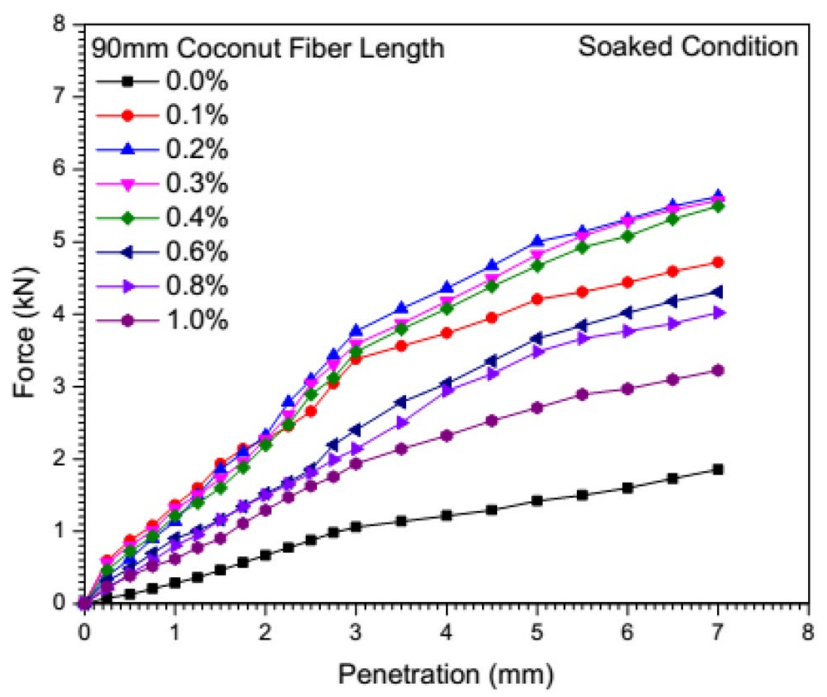

Fig. 9 Load-displacement relationships for $90 \mathrm{~mm}$ coconut fiber 
Table 5 Laboratory results of soaked CBR values for randomly reinforced soil

\begin{tabular}{lllll}
\hline $\begin{array}{l}\text { Fiber } \\
\begin{array}{l}\text { content } \\
(\%)\end{array}\end{array}$ & $\begin{array}{l}30 \mathrm{~mm} \\
\text { Coconut fiber } \\
\text { length }\end{array}$ & $\begin{array}{l}60 \mathrm{~mm} \\
\text { Coconut fiber } \\
\text { length }\end{array}$ & $\begin{array}{l}90 \mathrm{~mm} \\
\text { Coconut fiber } \\
\text { length }\end{array}$ & Palm fiber \\
\hline 0 & 7 & 7 & 7 & 7 \\
0.1 & 14 & 18 & 21 & 10 \\
0.2 & 18 & 22 & 25 & 14 \\
0.3 & 17 & 21 & 24 & 13 \\
0.4 & 16 & 19 & 23 & 12 \\
0.6 & 15 & 16 & 18 & 10 \\
0.8 & 14 & 14 & 17 & 9 \\
1.0 & 11 & 11 & 14 & 8 \\
\hline
\end{tabular}

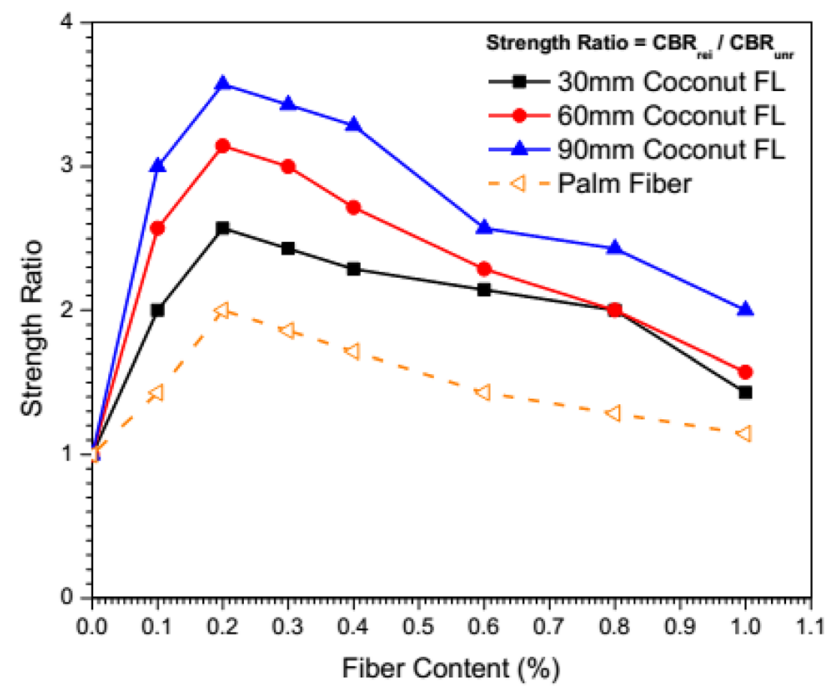

Fig. 10 Variation of CBR with fiber content

length reinforced soil are shown in Fig. 9. From the plot, the force-penetration relationship appears to be linear for penetration up to about $3 \mathrm{~mm}$. Table 5 is the summary of the Soaked CBR results.

The relative strength ratio is defined as the $C B R$ of the reinforced soil to the CBR of the unreinforced soil. Figure 10 shows the variations of the relative strength ratio of all the soaked CBR values with fiber contents, fiber lengths and fiber type for the reinforced soil. From Fig. 9, the maximum CBR value was attained at optimum fiber content value of $0.2 \%$. This increase in strength was observed for all the fiber lengths (thus $30 \mathrm{~mm}, 60 \mathrm{~mm}$ and $90 \mathrm{~mm}$ ) and fiber type. It appears the maximum strength ratio with fiber length was attained at $90 \mathrm{~mm}$ fiber length. However, beyond the $0.2 \%$ fiber content, there was a gradual reduction in the CBR values but they were all higher than the unreinforced soil with soaked CBR value of $7 \%$. The maximum strength ratio in soaked CBR values was 3.6 and 2 for
$90 \mathrm{~mm}$ coconut fiber length and palm fiber, respectively. This means that randomly reinforcing the lateritic soil with $0.2 \%$ of $90 \mathrm{~mm}$ coconut fiber and palm fiber increases the soaked CBR by 3.6 times and two times, respectively.

The increase in strength is attributed to the interactions between the fibers and the soil particles through mechanical interlocking of the randomly oriented discrete fibers and the lateritic soil mass. The interlocking process leads to the transfer of some amount of stresses imposed on the soil to the randomly distributed fibers through the mobilization of the tensile strength of the fibers. Based on this, the fiber-reinforced specimen functions well both as frictional and tension resistance constituent or unit. Lekha et al. [20] in a study of soil stabilization of lateritic soil by arecanut fiber also observed similar trend but the length of fiber used was $28 \mathrm{~mm}$. These trends in the results are similar to findings reported by Prabakar and Sridhar [29].

In Ghana, CBR is the most widely adopted strength parameter use for road design. The Department of Feeder Roads (DFR) [10] specification on Soils and Natural Gravels-A Guide for Area Engineers on low volume roads specifies a minimum CBR value of $15 \%$ for subgrade, $30 \%$ for subbase and $60 \%$ for base layers. From the test results, the highest $C B R$ values attained at $0.2 \%$ fiber content satisfy the requirement for a subgrade layer only but not for subbase and base. To further improve the soil-fiber composite in order to serve as subbase or base layer, the soil-fiber composite could be modified with cement or fly ash.

The results of this study have been compared with other additives previously used in Ghana to reinforce soil. Gawu and Gidigasu [13] study the effect of spent carbide on the geotechnical characteristics of lateritic soils from Kumasi, Ghana. The results showed that $10 \%$ spent carbide addition was suitable for stabilizing the soil. Lyon Associates Inc, 1971), stabilized lateritic soils from Ghana using cement and lime as additives. Soils stabilized with cement showed greater gains in strength than lime-stabilized soils. The generally established minimum CBR and UCS values were attained with $3 \%$ to $6 \%$ cement. Lime-stabilized gravels showed maximum strength gains with $4 \%$ to $6 \%$ lime.

\subsubsection{Unconfined compressive strength (UCS)}

Figure 11 shows typical stress-strain curves for specimen reinforced with $90 \mathrm{~mm}$ coconut fiber length. From the plot, the peak strength values appear to have been clearly defined at strains of about $5 \%$. Table 6 is the summary of the UCS test results. The relative strength ratio of the UCS is defined as the UCS of the reinforced soil to the UCS of the unreinforced soil. The relative Unconfined Compressive Strength (UCS) values are plotted against fiber content in Fig. 12. The plot indicates that the maximum 


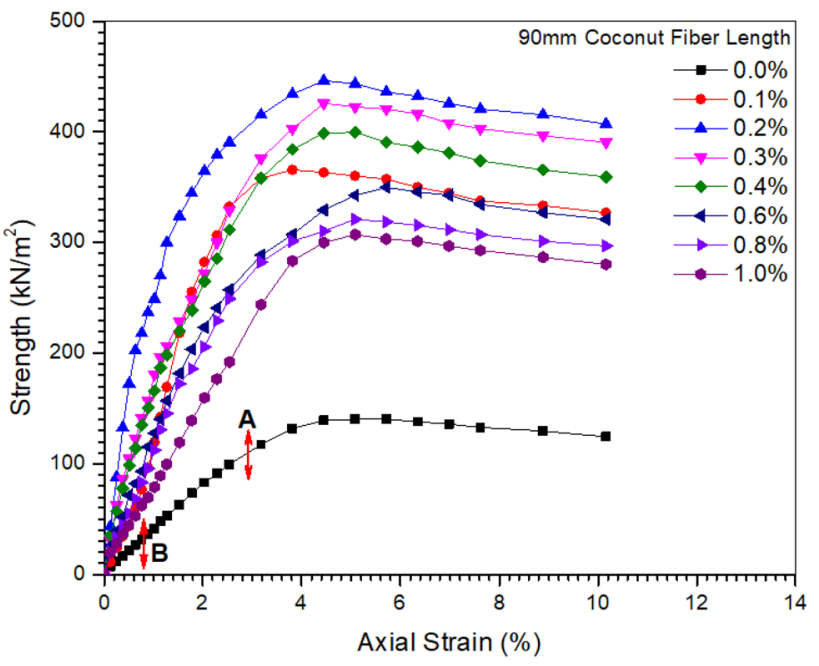

Fig. 111 Stress-strain relationships for $90 \mathrm{~mm}$ coconut fiber-reinforced UCS sample

UCS values were attained at $0.2 \%$ fiber content for the two fiber types. The UCS of the fiber-reinforced soil increased from $140 \mathrm{kPa}$ for the unreinforced soil to a maximum of $352 \mathrm{kPa}, 398 \mathrm{kPa}$ and $447 \mathrm{kPa}$ at coconut fiber length of $30 \mathrm{~mm}, 60 \mathrm{~mm}$ and $90 \mathrm{~mm}$, respectively. The maximum UCS value for palm fiber-reinforced soil was recorded to be $352 \mathrm{kPa}$. The increase in strength may be due to the increase in shear parameters.

At low fiber content, larger spacing is created between the fibers in the composite mix leading to a less effective fiber to soil net formation. When the fiber content was gradually increased, there was a decrease in spacing between the fibers in the composite mix which made the fiber-soil system to effectively form a strong fiber-soil net. Applied external forces were therefore transferred and carried by the fiber-soil net. This phenomenon was observed to be more effective at $0.2 \%$ fiber content. However, with an increase in the fiber content beyond the $0.2 \%$, a lot of the fiber filaments gather in clusters within the soil-fiber mix due to the strong affinity between the fibers which leads to more fiber to fiber interaction. The result of this is an increased tendency for the samples to fail by shearing as the fibers slip over each other creating planes of weak zones in the reinforced specimen. Two (2) different modes of sample failures were observed in the laboratory. Reinforced UCS samples with fiber contents from 0.1 to $0.3 \%$ failed by bulging in the middle portion of the sample as shown in Fig. 13. This resulted in the damaged samples reducing in height but increase in diameter. However, reinforced UCS samples with fiber contents from 0.4 to $1.0 \%$ failed by cracking as shown in Fig. 14. The cracks were in the diagonal direction from the top and bottom of the sample and gradually extended to the middle portion of the sample resulting in some of the surface blocks of the reinforced soil falling off. These cracks join together to form a predominant shear plane at failure. With increase

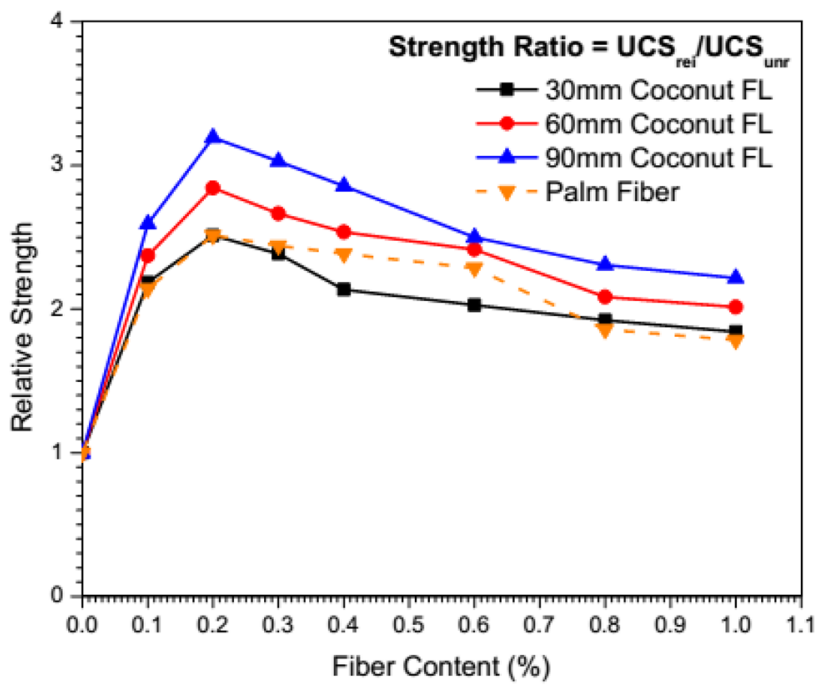

Fig. 12 Variation of relative UCS values with fiber content

Table 6 Laboratory results of UCS values of reinforced soil

\begin{tabular}{|c|c|c|c|c|c|c|c|c|}
\hline \multirow{2}{*}{$\begin{array}{l}\text { Fiber } \\
\text { content } \\
(\%)\end{array}$} & \multicolumn{2}{|c|}{$30 \mathrm{~mm}$ Coconut FL } & \multicolumn{2}{|c|}{$60 \mathrm{~mm}$ Coconut FL } & \multicolumn{2}{|c|}{$90 \mathrm{~mm}$ Coconut FL } & \multicolumn{2}{|l|}{ Palm fiber } \\
\hline & Peak UCS value & Stiffness (E) & Peak UCS value & Stiffness (E) & Peak UCS value & Stiffness (E) & Peak UCS value & Stiffness (E) \\
\hline 0 & 140 & 51 & 140 & 51 & 140 & 51 & 140 & 51 \\
\hline 0.1 & 306 & 148 & 332 & 154 & 363 & 163 & 300 & 147 \\
\hline 0.2 & 352 & 173 & 398 & 188 & 447 & 201 & 352 & 170 \\
\hline 0.3 & 334 & 160 & 373 & 171 & 424 & 186 & 342 & 163 \\
\hline 0.4 & 299 & 149 & 355 & 163 & 400 & 173 & 334 & 155 \\
\hline 0.6 & 284 & 142 & 338 & 157 & 350 & 160 & 320 & 150 \\
\hline 0.8 & 269 & 140 & 292 & 144 & 323 & 150 & 260 & 139 \\
\hline 1.0 & 258 & 135 & 282 & 138 & 310 & 142 & 250 & 132 \\
\hline
\end{tabular}




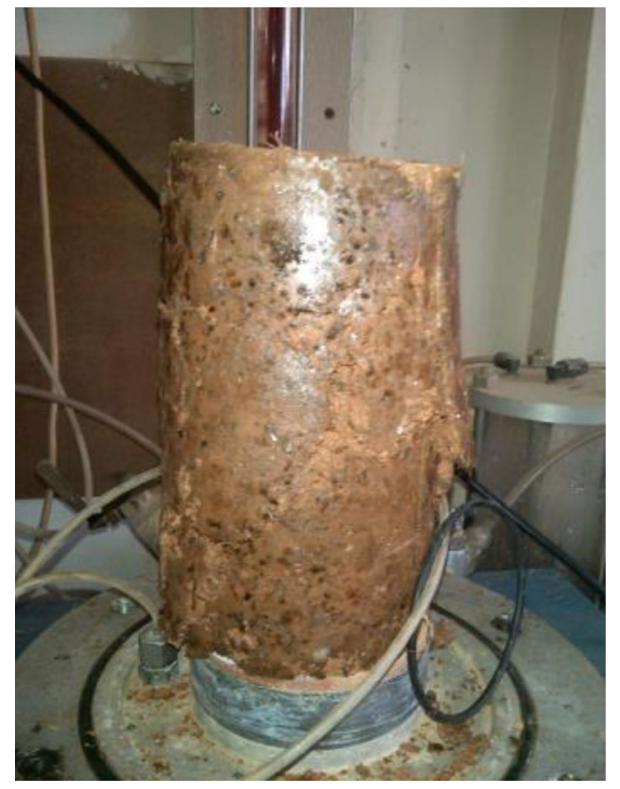

Fig. 13 Failure by bulging for $0.2 \%$ FC

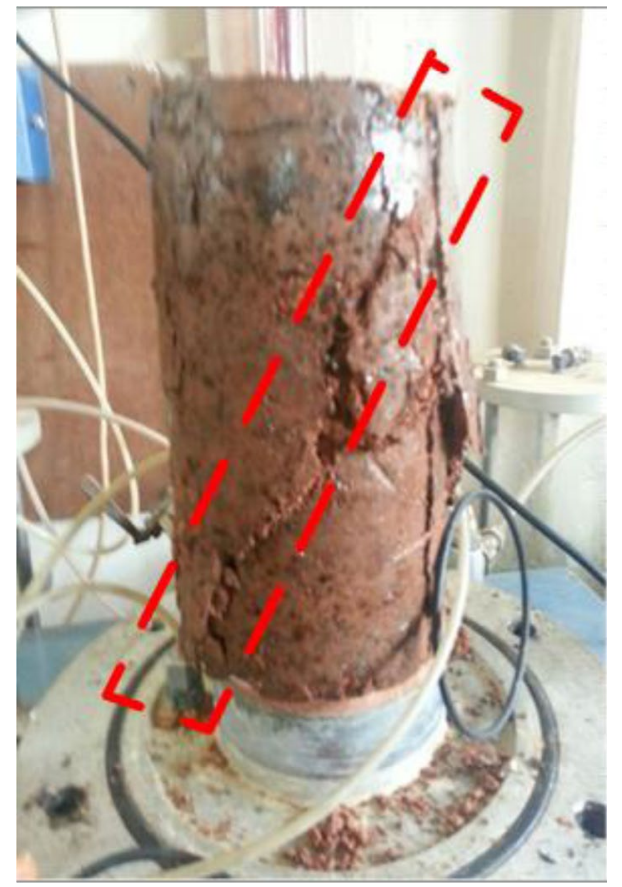

Fig. 14 Failure by shearing for $0.6 \%$ FC

in fiber content, the failure pattern of the reinforced soil changes from ductile to brittle.

With regard to coconut fiber inclusion, the effect of the length of fiber is examined in Fig. 15 by plotting the strength ratio against fiber length for both CBR and UCS. The plot shows that as the length of fiber increases, the strength ratio or the gain in strength increases. This

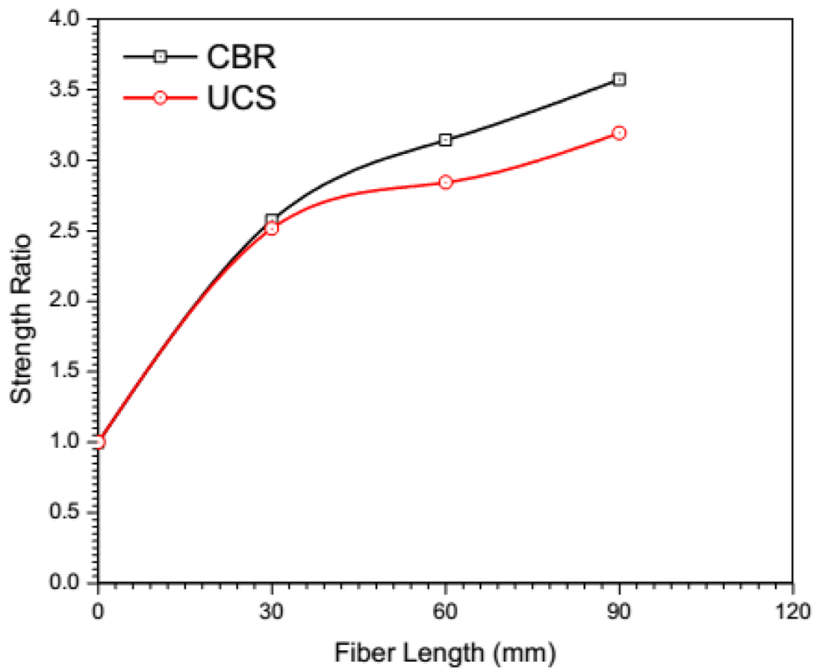

Fig. 15 Relative CBR and UCS values at $0.2 \%$ fiber content

suggests that the length of fiber is a major factor in improving the strength of the lateritic soil. From the plot, as the length of fiber increases the rate of increase in the strength reduces suggesting that there may be a fiber length beyond which the strength ratio does not increase.

\subsubsection{Effect of fiber on stiffness of the reinforced lateritic soil}

Stiffness modulus is used to measure the ability of soil to resist deformation. From Fig. 11, the stress-strain curves of the reinforced and unreinforced soil changes nonlinearly. According to Tang et al. [36], modulus is expressed as the slope of the linear portion of stress-strain curve. From Fig. 11, the connecting line segment BA is selected for each curve and the modulus (E) expressed using the formula:

$E=\frac{\Delta \sigma}{\Delta \varepsilon}=\frac{\sigma_{\mathrm{A}}-\sigma_{\mathrm{B}}}{\varepsilon_{\mathrm{A}}-\varepsilon_{\mathrm{B}}}$

where $\sigma_{\mathrm{A}}$ and $\sigma_{\mathrm{B}}$ are the stress of $\mathrm{A}$ and $\mathrm{B}$ corresponding to the strain $\varepsilon_{A}$ and $\varepsilon_{B}$. Table 6 shows summary of the stiffness modulus values for the different fiber contents and fiber type.

Figure 16 shows typical variation of the stiffness modulus values of $90 \mathrm{~mm}$ coconut fiber-reinforced soil at various strain levels. The stiffness modulus at a particular strain is evaluated by dividing the stress obtained at a particular strain with the corresponding strain. At low strain, it is observed that the stiffness is high at the initial stages and decreases as the strain levels increases. It is worthy to note that the stiffness of the reinforced soil increased with the increase in fiber content for both coconut fiber 


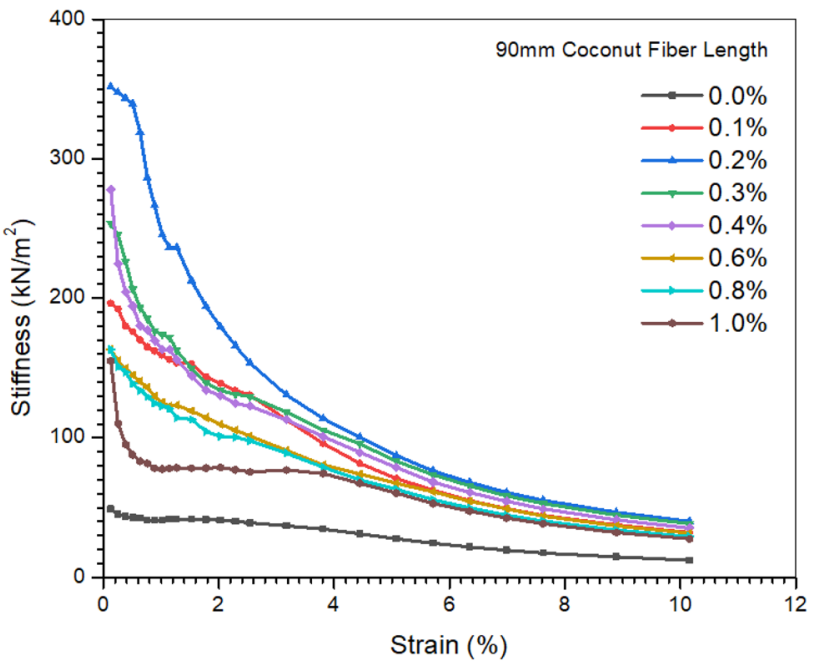

Fig. 16 Stiffness versus strain response for $90 \mathrm{~mm}$ fiber length

(irrespective of the fiber length) and palm fiber-reinforced soils up to $0.2 \%$ fiber content beyond which there is a gradual reduction in the stiffness. The stiffness-strain variations with the different fiber types and contents were roughly parallel to each other as shown in the case of the study soil reinforced with $90 \mathrm{~mm}$ coconut fiber length in Fig. 16. The general result shows that the stiffness of all the fiber-reinforced soil were higher than the stiffness of the unreinforced soil. The result of this study is similar to conclusions made by Li et al. [21] and Gullu and Khudir [16].

\section{Conclusion}

The application of randomly distributed natural fibers as potential reinforcement for weak lateritic subgrade soil for low volume roads was investigated. The 4-day-soaked CBR and UCS of the lateritic soil reinforced with and without coconut and palm fibers were compared to the Ghana Department of Feeder Roads specifications for low volume road. The main findings based on the study results are summarized as follows:

1. The maximum dry densities (MDD) of the lateritic soil decreased with increasing fiber content, whereas the optimum moisture content (OMC) increased with increasing fiber content.

2. With the increase in fiber content, both CBR and UCS of the reinforced soils increased first and then decreased. The peak CBR and peak UCS values were attained at optimum fiber content of $0.2 \%$ for both coconut fiber and palm fiber. At the optimum fiber content, the 4-day-soaked CBR of the reinforced soil was in a range of $18 \%$ to $25 \%$ at coconut fiber lengths of $30 \mathrm{~mm}$ to $90 \mathrm{~mm}$ compared to that of the unreinforced soil (having a CBR value of 7\%). The UCS values of the reinforced soil were 2.5, 2.8 and 3.2 times that of the unreinforced soil (having a UCS value of $140 \mathrm{kPa}$ ) for $30 \mathrm{~mm}, 60 \mathrm{~mm}$ and $90 \mathrm{~mm}$ coconut fiber lengths. With regard to palm fiber, maximum CBR and UCS values of $14 \%$ and $352 \mathrm{kPa}$ were attained at the optimum fiber content.

3. The coconut fiber-reinforced soil showed maximum gain in strength compared to that of the palm fiberreinforced soil. This improved strength occurred at the highest fiber length of $90 \mathrm{~mm}$ which shows fiber length is key to strength mobilization in reinforced soil.

In summary, the study has revealed that the application of randomly distributed natural fibers in reinforcing weak lateritic soil has the potential for improving the geotechnical characteristics of the raw soil significantly. Based on the CBR as well as economic and environmental benefits, $0.2 \%$ fiber content is recommended as the optimum to reinforce the weak lateritic soil for subgrade layer of low-volume roads as it satisfies the minimum CBR requirement of $15 \%$.

Funding On behalf of the authors, the corresponding author states there was no funding for the work but the work was out of authors academic research.

\section{Declarations}

Conflict of interest On behalf of all authors, the corresponding author states there is no conflict of interest.

Open Access This article is licensed under a Creative Commons Attribution 4.0 International License, which permits use, sharing, adaptation, distribution and reproduction in any medium or format, as long as you give appropriate credit to the original author(s) and the source, provide a link to the Creative Commons licence, and indicate if changes were made. The images or other third party material in this article are included in the article's Creative Commons licence, unless indicated otherwise in a credit line to the material. If material is not included in the article's Creative Commons licence and your intended use is not permitted by statutory regulation or exceeds the permitted use, you will need to obtain permission directly from the copyright holder. To view a copy of this licence, visit http://creativecommons. org/licenses/by/4.0/.

\section{References}

1. Abhijith RP (2015) Effect of natural coir fibers on CBR strength of soil subgrade. Int J Sci Res Publ 5(4):1-4

2. ASTM D 1557-91 (1991) Standard test method for laboratory compaction characteristics of soil using modified effort American society for testing materials annual book of ASTM standards. vol 04.08. Philadelphia, $8 \mathrm{pp}$ 
3. ASTM D 1883-99 (1999) Standard test method for CBR (California Bearing Ration) of laboratory compacted soil. ASTM International, West Conshohocken, PA

4. ASTM D 2166-98a (1998) Standard test method for unconfined compressive strength of cohesive soil.

5. Babu S, Vasudevan K (2008) Strength and stiffness response of coir fiber-reinforced tropical soil. J Mater Civ Eng ASCE 20(9):571-577

6. BS (1990) Method of testing soils for civil engineering purposes. British Standards Institution, London

7. Chaple MP, Dhatrak AI (2013) Performance of coir fiber reinforced clayey soil. Int J Eng Sci 2(4):54-64

8. Charan HD, Ranjan G, Vasan RM (1995) Strength characteristics of coir fiber reinforced sand. In: Proceedings-Indian GeotechConference, Bangalore, India, vol 1. pp 339-342

9. Cyrus S, Babu TJ (2005) Consolidation characteristics of coir reinforced Cochin marine clays. In: Proceedings of Indian Geotech-Conference, Ahmedabad, India. pp 125-128

10. DFR (2006) Soils and natural gravels a guide for area engineers. Ghana Ministry of Transport - Department of Feeder Roads

11. Enokela OS, Alada PO (2012) Strength analysis of coconut fiber stabilized earth for farm structures. Int J Adv Res Technol 1(2):1-7 (ISSN 2278-7763)

12. Faure AG, Da Mata JDV (1994) Penetration resistance value along compaction curves. ASCE J Geotech Eng 20:46-59

13. Gawu SKY, Gidigasu SSR (2013) The effect of spent carbide on the geotechnical characteristics of two lateritic soils from the Kumasi Area. Int J Eng Res Technol 6(3):311-321 (ISSN 0974-3154)

14. Ghavami K, Filho R, Barbosa P (1999) Behaviour of composite soil reinforced with natural fibers. Cem Concr Compos 21:39-48

15. Gidigasu MD (1975) Behaviour of lateritic soils in road-a review. Ghana Eng J Ghana Inst Eng 7(1):52-78

16. Gullu H, Khudir A (2018) Effects of freeze-thaw cycles on mechanical properties of polypropylene fiber and cement stabilized clay. Cold Reg Sci Technol 154:155-165

17. Hua $L$ (2001) The family of compaction curves for fine-grained soils and their engineering behaviors. Ph.D. Thesis, Department of Civil and Environmental Engineering, University of Alberta

18. Kumar R, Kanaujia VK, Chandra D (1999) Engineering behaviour of fibrereinforced pond ash and silty sand. Geosynth Int 6(6):509-518

19. Kumar P, Mehndiratta HC, Chandranarayana S, Singh SP (2005) Effect of randomly distributed fibres on flyash embankments. IEI J CV 86:113-118

20. Lekha BM, Goutham S, Shankar AUR (2014) Evaluation of lateritic soil stabilized with arecanut coir for low volume pavements. https://doi.org/10.1016/j.trgeo.2014.09.001

21. Li L, Shao W, Li Y, Cetin B (2015) Effects of climatic factors on mechanical properties of cement and fiber reinforced clays. Geotech Geol Eng 33(3):537-548
22. Lyon Associates, Inc. and Building and Road Research Institute (1971) Laterite and lateritic soils and other problem soils of Africa. Lyon Associates, Baltimore. USAID/csd./2164.

23. Mali S, Singh B (2014) Strength behaviour of cohesive soils reinforced with fibers. Int J Civ Eng Res 5(4):353-360

24. Marandi SM, Bagheripour MH, Rahgozar R, Zare H (2008) Strength and ductility of randomly distributed palm fibers reinforced silty-sand soils. Am J Appl Sci 5(3):209-220

25. Mattone R (2005) Sisal fibre reinforced soil with cement or cactus pulp in bahareque technique. Cem Concr Compos 27:611-616

26. Mitchell JK, Soga K (2005) Fundamentals of soil behavior, vol 3. Wiley, New York

27. MoT (2007) Standard specification for road and bridge works. Ghana Ministry of Transport

28. Muthu SL, Sasikala S, Padmavathi V, Priya S, Saranya V (2018) Utilization of coconut coir fibre for improving subgrade strength characteristics of clayey sand. Int Res J Eng Technol 05(04):2873-2878

29. Prabakar J, Sridhar RS (2002) Effect of random inclusion of sisal fibre on the strength behavior of soil. Constr Build Mater 16:123

30. Pradhan PK, Kar RK, Naik A (2012) Effect of random inclusion of polypropylene fibers on strength characteristics of cohesive soil. Geotech Geol Eng 30(1):15-25

31. Ramesh HN, Manoj Krishna KV, Mamatha HV (2010) Compaction and strength behavior of lime-coir fiber treated Black Cotton soil. Geomech Eng 2(1):19-28

32. Santhi KK, Sayida MK (2009) Behaviour of black cotton soil reinforced with sisal fibre. In: 10th National conference on technological trends (NCTT09). pp 6-7

33. Singh RR, Mittal S (2014) Improvement of local subgrade soil for road construction by the use of coconut coir fiber. Int J Res Eng Technol 3(5):707-711

34. Sreekumar MG, Deepa GN (2013) Stabilized lateritic blocks reinforced with fibrous coir wastes. Int J Sustain Constr Eng Technol 4(2):23-32 (ISSN: 2180-3242)

35. Stuti M, Sharma AK, Jain PK, Rakesh Kumar R (2015) Review on stabilization of soil using coir fiber. Int J Eng Res 4(6):296-299

36. Tang L, Cong S, Geng L, Ling X, Gan F (2018) The effect of freezethaw cycling on the mechanical properties of expansive soils. Cold Reg Sci Technol 145:197-207

37. Vidal H (1969) The principle of reinforced earth. Highw Res Rec 282:1-16

38. Zornberg JG (2002) Discrete framework for limit equilibrium analysis of reinforced soil. Geotechnique 52(8):593-604

Publisher's Note Springer Nature remains neutral with regard to jurisdictional claims in published maps and institutional affiliations. 